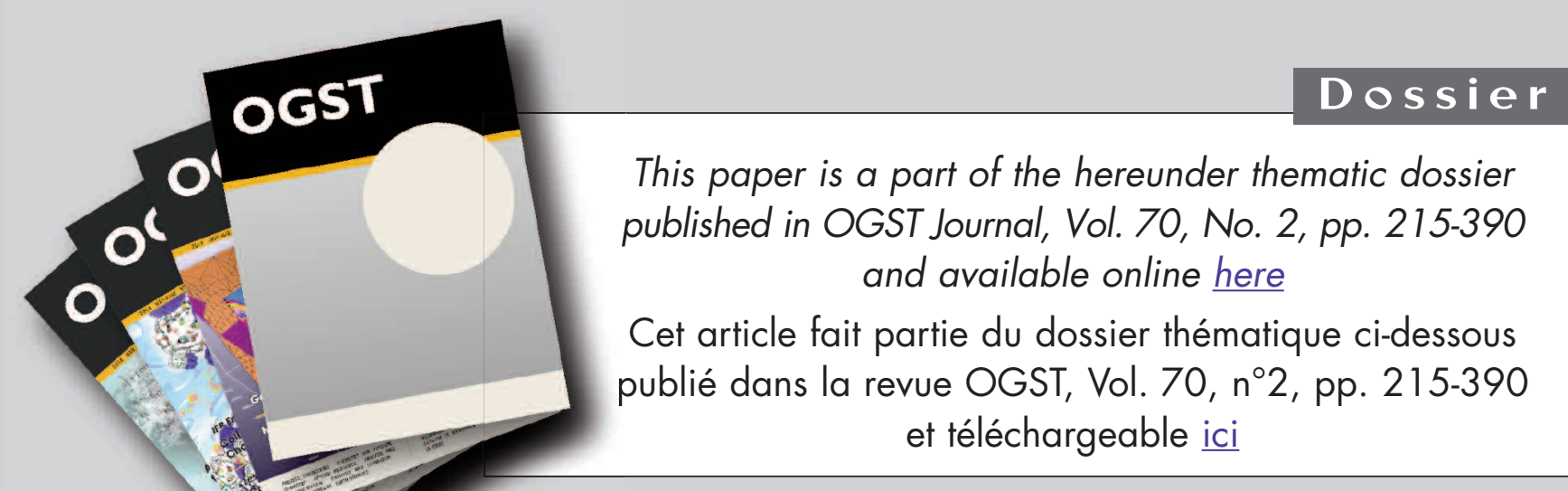

DOSSIER Edited by/Sous la direction de : B. Dewimille

Fluids-Polymers Interactions: Permeability, Durability

Interactions fluides polymères : perméabilité, durabilité

Oil \& Gas Science and Technology - Rev. IFP Energies nouvelles, Vol. 70 (2015), No. 2, pp. 215-390

Copyright (C) 2015, IFP Energies nouvelles

$215>$ Tribute to Yves Chauvin Hommage à Yves Chauvin

S. Candel and 0 . Appert

$219>$ Editorial

G. Kimmerlin

227 > Gas Permeation in Semicrystalline Polyethylene as Studied by Molecular Simulation and Elastic Model

Perméation de gaz dans le polyéthylène semi-cristallin par simulation moléculaire et modèle élastique

P. Memari, V. Lachet and B. Rousseau

237 > Reinforcement of the Gas Barrier Properties of Polyethylene and Polyamide Through the Nanocomposite Approach: Key Factors and Limitations

Renforcement des propriétés barrière aux gaz de matrices polyéthylène et polyamide par l'approche nanocomposite : facteurs clés et limitations E. Picard, J.-F. Gérard and É. Espuche

251 > Diffuso-Kinetics and Diffuso-Mechanics of Carbon Dioxide / Polyvinylidene Fluoride System under Explosive Gas Decompression: Identification of Key Diffuso-Elastic Couplings by Numerical and Experimental Confrontation

Cinétique de diffusion et comportement diffuso-mécanique du système dioxide de carbone / polyfluorure de vinylidène sous décompression explosive de gaz : identification des couplages diffuso-élastiques majeurs par confrontation numérique et expérimentale

J.-C. Grandidier, C. Baudet, S. A. E. Boyer, M.-H. Klopffer and L. Cangémi

267 > Characterization of Polymer Layered Silicate Nanocomposites by Rheology and Permeability Methods: Impact of the Interface Quality

Caractérisation de nanocomposites polymère silicate par des méthodes de rhéologie et de perméabilité : rôle de la qualité de l'interface

R. Waché, M.-H. Klopffer and S. Gonzalez

$279>$ Evaluation of Long Term Behaviour of Polymers for Offshore Oil and Gas Applications

Durabilité des polymères pour application pétrolière offshore

P.-Y. Le Gac, P. Davies and D. Choqueuse

$291>$ Development of Reactive Barrier Polymers against Corrosion for the Oil and Gas Industry: From Formulation to Qualification through the Development of Predictive Multiphysics Modeling

Développement de matériaux barrières réactifs contre la corrosion pour l'industrie pétrolière : de la formulation à la qualification industrielle en passant par le développement de modèles multiphysiques prédictifs

X. Lefebvre, D. Pasquier, S. Gonzalez, T. Epsztein, M. Chirat and F. Demanze
$305>$ Development of Innovating Materials for Distributing Mixtures of Hydrogen and Natural Gas. Study of the Barrier Properties and Durability of Polymer Pipes

Développement de nouveaux matériaux pour la distribution de mélanges de gaz naturel et d'hydrogène. Étude des propriétés barrière et de la durabilité de tubes polymères

M.-H. Klopffer, P. Berne and É. Espuche

317 > New Insights in Polymer-Biofuels Interaction

Avancées dans la compréhension des interactions polymères-biocarburants E. Richaud, F. Diouani, B. Fayolle, J. Verdu and B. Flaconneche

$335>$ Biofuels Barrier Properties of Polyamide 6 and High Density Polyethylene Propriétés barrière aux bio essences du polyamide 6 (PA6) et du polyéthylène haute densité (PEHD)

L.-A. Fillot, S. Ghiringhelli, C. Prebet and S. Rossi

353 > Permeability of EVOH Barrier Material used in Automotive Applications: Metrology Development for Model Fuel Mixtures

Perméabilité d'un matériau barrière EVOH utilisé dans des applications automobiles : développement métrologique pour des mélanges modèles de carburants

J. Zhao, C. Kanaan, R. Clément, B. Brulé, H. Lenda and A. Jonquières

367 > Effects of Thermal Treatment and Physical Aging on the Gas Transport Properties in Matrimid ${ }^{\circledR}$

Les effets du traitement thermique et du vieillissement physique sur les caractéristiques du transport au gaz dans le Matrimid ${ }^{\circledR}$

L. Ansaloni, M. Minelli, M. Giacinti Baschetti and G. C. Sarti

381 > Separation of Binary Mixtures of Propylene and Propane by Facilitated Transport through Silver Incorporated Poly(Ether-Block-Amide) Membranes Séparation de mélanges binaires de propylène et de propane par transport au travers des membranes de poly(éther-blocamide) incorporant de l'argent R. Surya Murali, K. Yamuna Rani, T. Sankarshana, A. F. Ismail and S. Sridhar 


\title{
Development of Innovating Materials for Distributing Mixtures of Hydrogen and Natural Gas. Study of the Barrier Properties and Durability of Polymer Pipes
}

\author{
Marie-Hélène Klopffer ${ }^{1 *}$, Philippe Berne ${ }^{2}$ and Éliane Espuche ${ }^{3}$ \\ ${ }^{1}$ IFP Energies nouvelles, 1-4 avenue de Bois-Préau, 92852 Rueil-Malmaison Cedex - France \\ 2 CEA, LITEN, DTNM, LCSN, 38054 Grenoble - France \\ ${ }^{3}$ Université Lyon 1, CNRS, UMR5223, Ingénierie des Matériaux Polymères, 15 Bd A. Latarjet, 69622 Villeurbanne - France \\ e-mail: marie-helene.klopffer@ifpen.fr - philippe.berne@cea.fr - eliane.espuche@univ-lyon 1.fr \\ * Corresponding author
}

\begin{abstract}
With the growing place taken by hydrogen, a question still remains about its delivery and transport from the production site to the end user by employing the existing extensive natural gas pipelines. Indeed, the key challenge is the significant $\mathrm{H}_{2}$ permeation through polymer infrastructures (PolyEthylene (PE) pipes, components such as connecting parts). This high flow rate of $\mathrm{H}_{2}$ through $P E$ has to be taken into account for safety and economic requirements.

A 3-year project was launched, the aim of which was to develop and assess material solutions to cope with present problems for hydrogen gas distribution and to sustain higher pressure compared to classical high density polyethylene pipe. This project investigated pure hydrogen gas and mixtures with natural gas (20\% of $\mathrm{CH}_{4}$ and $80 \%$ of $\left.\mathrm{H}_{2}\right)$ in pipelines with the aim to select engineering polymers which are more innovative than polyethylene and show outstanding properties, in terms of permeation, basic mechanical tests but also more specific characterizations such as long term ageing and behaviour. The adequate benches, equipments and scientific approach for materials testing had been developed and validated.

In this context, the paper will focus on the evaluation of the barrier properties of 3 polymers ( $P E$, $P A 11$ and $P A H M)$. Experiments were performed for pure $\mathrm{H}_{2}$ and $\mathrm{CH}_{4}$ and also in the presence of mixtures of hydrogen and natural gas in order to study the possible mixing effects of gases. It will report some round-robin tests that have been carried out. Secondly, by comparing data obtained on film, polymer membrane and on pipe section, the influence of the polymer processing will be studied. Innovative multilayers systems will be proposed and compared on the basis of the results obtained on monolayer systems. Finally, the evolution of the transport properties of the studied polymers with an ageing under representative service conditions will be discussed.
\end{abstract}

Résumé - Développement de nouveaux matériaux pour la distribution de mélanges de gaz naturel et d'hydrogène. Étude des propriétés barrière et de la durabilité de tubes polymères - Avec la place croissante prise par l'hydrogène se pose la question de son transport et de sa distribution par le très vaste réseau existant de conduites de gaz naturel. Le principal verrou à lever est le taux de perméation sensiblement plus fort pour l'hydrogène, à travers les parois des canalisations qui sont essentiellement en PolyÉthylène (PE). Il en résulte des implications potentielles en termes de sécurité mais aussi de pertes économiques. 
Un projet d'une durée de trois ans a été lancé avec pour objectifs de proposer et de qualifier des polymères plus performants et innovants que le PE vis-à-vis de cette introduction massive d'hydrogène mais aussi capables de supporter des niveaux de pression plus élevés. Différents polymères ont été caractérisés en termes de propriétés barrière, de comportement mécanique, mais également de comportement en vieillissement vis-à-vis de l'hydrogène pur ou en mélange avec le gaz naturel $(20 \%$ de méthane pour $80 \%$ d'hydrogène). Les bancs d'essais, les équipements et les procédures nécessaires pour ces tests de matériaux ont été développés et validés.

Dans ce contexte, l'article se concentrera sur l'évaluation des propriétés barrière de 3 polymères : PE, PA11 et PAHM. Il rendra compte d'essais de comparaison interlaboratoires qui ont été menés. Les expériences en hydrogène et méthane purs ou combinés permettront de quantifier les éventuels effets de mélange. En second lieu, l'influence de la mise en forme sera établie grâce à la comparaison des données obtenues sur des films fins, des membranes ou des tronçons de tube. Des solutions innovantes de systèmes multicouches seront proposées et comparées sur la base des résultats obtenus en monocouches. Enfin, l'article discutera l'évolution des propriétés de transport des polymères étudiés sous l'effet d'un vieillissement en conditions de service représentatives.

\section{INTRODUCTION}

With the development of hydrogen as an energy vector, its delivery and transport from the production site to the end user remains an issue. Indeed, new steel pipeline is cost intensive and the use of existing natural gas infrastructure raises the question of its durability in presence of hydrogen for metallic parts and its tightness for polymer parts, respectively. Actually, the key challenge is the high hydrogen permeation rate through existing polymer infrastructures used for natural gas distribution (PolyEthylene (PE) pipes, components as connecting parts) due to its small size in comparison with methane [1]. Due to safety and economic reasons, one of the main concerns is to limit leakage of hydrogen by permeation through the pipe.

The project called PolHYtube was relative to the development and study of innovating materials for hydrogen distribution networks and has benefited from a grant by the French National Research Agency (ANR, Agence Nationale de la Recherche). It has involved several industrial and academic partners. This 3 -year project has investigated pure hydrogen and gas mixtures $\left(20 \% \mathrm{CH}_{4}-80 \% \mathrm{H}_{2}\right)$ in pipelines made of engineering polymers to develop and assess material solutions to cope with current problems for $\mathrm{H}_{2}$ distribution and to sustain higher pressure compared to classical high density polyethylene pipe.

Test benches and protocols for testing materials in terms of mechanical and barrier properties were first developed and validated on reference materials [2]. Materials such as a High Density PolyEthylene (HDPE) and PolyAmide 11 (PA11) have been studied. HDPE is a semi-crystalline polymer considered as a reference material as it is used today in natural gas distribution pipes. PA11 should allow a higher operating pressure combined with better gas-barrier performances.

On the other hand, technical polymers and assemblies (other semi-crystalline or amorphous thermoplastics, multi-layers, polymer blends, etc.) have been proposed and studied to improve gas-barrier performances compared to polyethylene [3]. Step by step, permeation and basic mechanical tests have been performed and then more specific characterisations have been done for long-term ageing under various conditions in order to finally determine the materials that could meet all the specifications required by hydrogen distribution. The design of a pipe prototype was also carried out at the end of the project and an economic study was performed for the different potential solutions [2, 4].

One of the objectives of this paper is to evaluate the impact of hydrogen introduction in the existing natural gas infrastructures in terms of modification of the polymer pipes barrier properties in comparison with natural gas. For this purpose, the transport properties of HDPE films of different thicknesses in presence of pure hydrogen but also with mixtures of natural gas and hydrogen have been measured in different conditions of temperature and pressure and moreover, in different laboratories (IFP Energies nouvelles, IMP, CEA). Furthermore, a specific device for the evaluation of hydrogen permeability of pipes has been developed at IFP Energies nouvelles (IFPEN) to test them under hydrogen in service conditions. This apparatus allowed us to perform experiments on pipes sections in more realistic operating conditions. 
By comparing data obtained on film and pipes sections samples exposed to various temperatures, pressures and particularly different mixtures of natural gas and hydrogen, it was possible to evaluate the influence of the polymer processing on its barrier properties.

An important point has also concerned the evolution of the material barrier properties with time and with exposure to hydrogen. Therefore, the properties of the unaltered material and of samples after ageing in presence of hydrogen in various conditions were compared to assess the long term behaviour in service. After a brief review of the equipments specifically developed by $C E A$ for this type of study, the results obtained on both PE100 and PA11 will be presented.

The last item of the paper is relative to the evaluation of innovative systems (such as other thermoplastics, multilayers) with enhanced barrier characteristics in comparison with PA11 and HDPE reference materials and the detailed analysis of their respective behaviour at different temperatures and hydrogen pressures.

\section{GAS PERMEATION THEORY}

In a general way, gas permeation in a polymer can be defined as the susceptibility of this material to be penetrated and crossed by the gas molecules. It is described by a solution-diffusion mechanism. At a given temperature, the transport of a gas molecule through a homogeneous polymer matrix can be described as a three-step process $[1,5]$ : sorption of the component at the upstream face of the membrane, followed by diffusion/solution through the material cross section under the influence of the applied driving force (pressure gradient which corresponds to a chemical potential gradient) and finally desorption at the downstream face of the film [6]. In a Fickian transport mechanism, the interfacial equilibrium is supposed to be fast compared to the diffusion step, which is then the governing step of the transport mechanism. Both the solubility and diffusion parameters are dependent on the characteristics of the membrane material and the gases, and can be studied separately with various sorption and diffusion models [1, 6-12].

The permeability coefficient, denoted $P e$, is, in a Fickian mechanism, the product of the solubility coefficient, $S$, and the diffusion coefficient, $D$ :

$$
P e=D S
$$

Diffusion is the process by which a small molecule (organic liquids, vapours, gases, etc.) is transferred in the system due to random molecular motions. Therefore, $D$ is a kinetic term that is related to the free volume and the molecular mobility in the polymer phase.
The solubility coefficient has a thermodynamic origin and depends on the molecule-polymer interactions, on the polymer free volume as well as on the ability of the gas to condense. It is related to the local concentration of the gas $C$ dissolved in the polymer and to the gas pressure by the following relation:

$$
C=S p
$$

Generally, the units are the following: $D$ is given in $\left(\mathrm{cm}^{2} / \mathrm{s}\right), S$ in $\mathrm{cm}^{3}(\mathrm{STP}) / \mathrm{cm}^{3}$ polymer.bar, $\mathrm{C}$ in $\mathrm{cm}^{3}(\mathrm{STP}) / \mathrm{cm}^{3}$ polymer. Consequently, $P e$ is expressed in $\mathrm{cm}^{3}$ (STP)/cm.s.bar.

Barrer [13] was the first one who showed that the diffusion of small size molecules in rubbery polymers is a thermally activated process. A great number of data in literature suggests that the transport coefficients (namely $S, D$ and $P e$ ) depend on the temperature, at a given pressure, via Arrhenius's law on a narrow range of temperature [11]:

$$
\begin{gathered}
S(T)=S_{0} \exp \left(-\frac{\Delta H_{S}}{R T}\right) \\
D(T)=D_{0} \exp \left(-\frac{E_{D}}{R T}\right) \\
P e(T)=P e_{0} \exp \left(-\frac{E_{P}}{R T}\right)
\end{gathered}
$$

The pre-exponential terms represent the limit values of the various coefficients of transport for an infinite molecular agitation $(T \rightarrow \infty)$. $E_{P}$ represents the apparent activation energy for the permeation process and is equal to the sum of $E_{D}$, the apparent activation energy of the diffusion process, and $\Delta H_{S}$, the heat of solution needed for the dissolution of a permeant mole in the matrix. These parameters depend on the chemical structure and on the morphology of the polymer matrix: amorphous or semicrystalline structure, value of the temperature relative to the characteristic temperatures such as the glass transition temperature $T g$ and the melting temperature $T m$.

Gas permeability rates are essential properties for the use of polymers for gas distribution and transport pipes. The improvement in their barrier performance implies that either $D$ or $S$ presents a very low value in the operating conditions. For that reason, semicrystalline polymers are interesting candidates due to their morphology and structure. Indeed gas transport through semicrystalline polymers is generally studied in the context of the two-phase model proposed and developed by Michaels and Parker [14] and Michaels and Bixler [15, 16]. 
For isotropic HDPE with spherulitic structures, these authors have shown that the sorption and the diffusion took place exclusively in the amorphous regions. The crystalline zones act as excluded volumes for the sorption process and are impermeable barriers for the diffusion process.

The gas barrier properties of polymeric materials can be controlled by different parameters. The degree of crystallinity is an important parameter and as the sorption and diffusion processes take place in the amorphous phase of the polymer, its chemical structure is a key point to take into account [1], explaining why important variations can be observed in the resulting barrier properties.

The aim of this work is to determine the hydrogen and methane permeability in a wide range of temperature (from 10 to $85^{\circ} \mathrm{C}$ ) and pressure (from 5 to 20 bar) for different thermoplastic semicrystalline polymers that could be used as alternative to HDPE in target pipeline. The evolution of the barrier properties after an ageing performed in an hydrogen environment was also studied for some polymers, and multilayer systems based on the most interesting materials were also proposed.

\section{EXPERIMENTAL SECTION}

\subsection{Materials}

An important point to be taken into account for the initial choice of the base thermoplastic polymers is their easy processing by extrusion or co-extrusion. As a technical plastics producer, Arkema participated in this project and provided some polymer materials. In particular, Arkema shared with the other partners its experience in developing polyamide 11 pipes for gas distribution in US. This allows the project team to well define the technical targets and specifications of the project (pipe diameter, pipe design (i.e. the thickness to diameter ratio), internal pressure).

Three thermoplastic polymers have been evaluated as base materials:

- a high density polyethylene HDPE (PE100 grade- PE XS10B from Total Petrochemical) currently used for natural gas distribution in Europe. It has been taken as the reference material for this study;

- two polymers of the polyamide family:

- PA11 (Rilsan TL): which is the material proposed by Arkema for making gas distribution pipes in US;

- PAHM: a polyamide with higher mechanical properties, under development by Arkema.

Extruded films (thickness around $1 \mathrm{~mm}$ ) as well as monolayer pipes with lengths up to $1 \mathrm{~m}$ and sections of $6 / 8$ and 26/32 (internal/external diameter in $\mathrm{mm}$ ) have been provided for each of these base materials to be studied under permeation conditions.

In addition to these base materials, more complex systems consisting of multilayer systems have also been studied. For this second route, Ethylene Vinyl Alcohol $(\mathrm{EVOH})$, which is known for its high gas barrier properties [17] has been combined with the base materials to improve their properties. Their structure was the following Polymer/EVOH/Polymer with an additive to promote adhesion between EVOH and the polymer matrix.

\subsection{Morphology Characterization}

The characteristic thermal parameters of HDPE, PA11 and PAHM materials have been determined by Differential Scanning Calorimetry (DSC). The analyses were performed at $10^{\circ} \mathrm{C} / \mathrm{min}$ with a DSC 2020 apparatus from TA Instruments. Samples of about $10 \mathrm{mg}$ were taken from extruded sheets of $1 \mathrm{~mm}$ thickness. To take off the water eventually contained in the polar films, PA11 and PAHM samples were dried 1 night at $60^{\circ} \mathrm{C}$ under vacuum before analysis. All samples were semi crystalline samples with a melting temperature of $128^{\circ} \mathrm{C}$, $189^{\circ} \mathrm{C}$ and $247^{\circ} \mathrm{C}$ for HDPE, PA11 and PAHM, respectively. The crystallinity rates have been calculated for HDPE and PA11 from the melting enthalpy $\left(\Delta H_{m}\right)$ and $\Delta H_{\infty}$ according to the law:

$$
X_{c}=\frac{100 \Delta H_{m}}{\Delta H_{\infty}}
$$

with $\Delta H_{\infty}$ equal to $290 \mathrm{~J} / \mathrm{g}$ and $226 \mathrm{~J} / \mathrm{g}$ for HDPE and PA11, respectively. $X_{c}$ is equal to $58 \pm 2 \%$ and $20 \pm 2 \%$ for HDPE and PA11, respectively. It is noteworthy that the glass transition temperature of these materials is equal to $-120^{\circ} \mathrm{C}$ and $47^{\circ} \mathrm{C}$, respectively.

The thermograms relative to PAHM exhibited a $\Delta C p$ change at $80^{\circ} \mathrm{C}$ assigned to the glass transition temperature. Moreover, the DSC analysis performed on PAHM showed a very small endothermic peak, meaning that the crystallinity rate of this material was very small in comparison with the one of PE and PA11. It was not possible to determine the crystallinity rate of this material due to the unknown value of $\Delta H_{\infty}$ for this material.

\subsection{Permeation Measurements}

Due to safety requirements, one of the main concerns about polymer pipes is their permeability to hydrogen, which may induce critical leakages of gaseous hydrogen. Permeation measurements were performed by IFPEN, $C E A$ and $I M P$ for hydrogen but also for pure methane 
and $\mathrm{H}_{2} / \mathrm{CH}_{4}$ mixtures in various conditions of pressure, temperature and gas mixtures compositions.

The experimental technique available at IFPEN concerns gas or gas mixtures permeation through a polymer membrane or a pipe section, in a flowing stream of vector gas and detection by gas chromatography. In that kind of measurement, one or several diffusing species cross the polymer to reach an opened cavity swept away by an inert gas stream. This carrier gas fulfils its purpose by transporting the different molecules towards an appropriate detector measuring the present gas proportion. Then, it is possible to determine the intrinsic transport coefficients of each of the gases constituting the

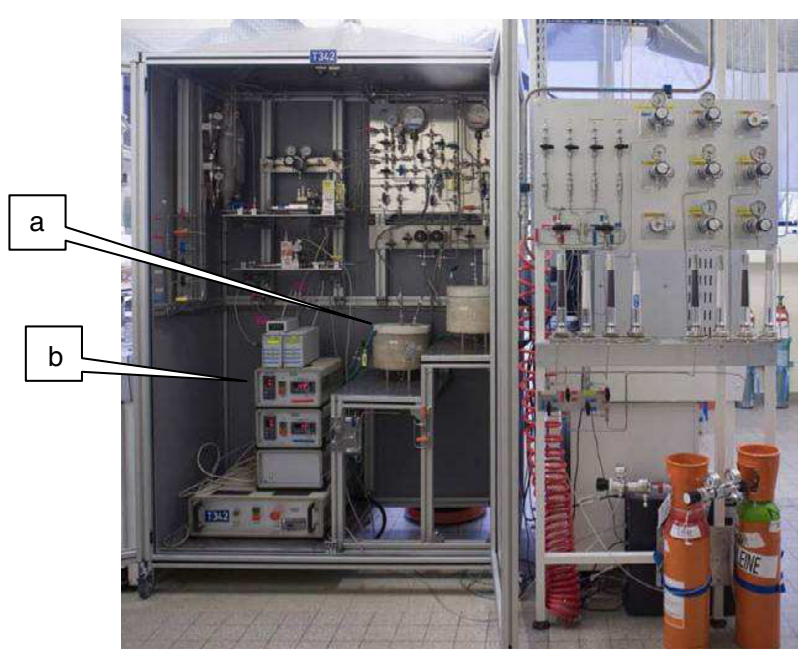

Figure 1

Permeation device dedicated to polymer membranes at IFPEN with a) one permeation cell and b) the temperature regulation.

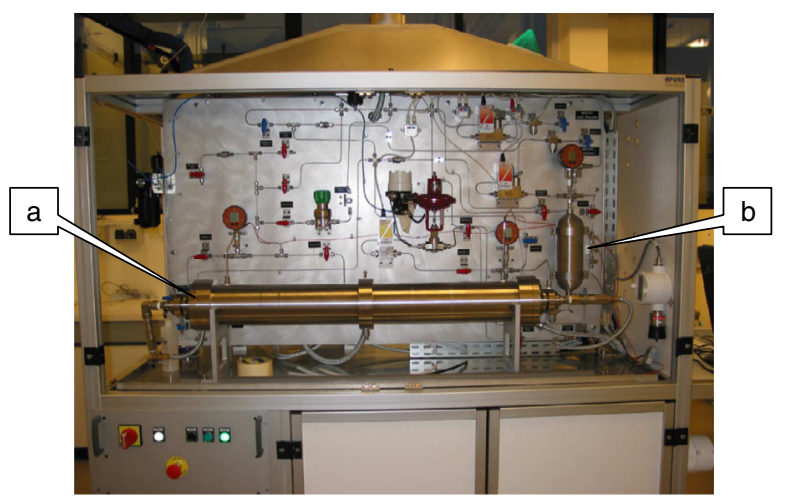

initial mixture. It allows determination of the permeability coefficients of pure gas in numerous polymers but also the permeability coefficients of gas mixtures, such as $\mathrm{CH}_{4}-\mathrm{H}_{2}[18,19]$. Practically, many permeability tests ( $>70$ ) were carried out during this study in order to identify the influence of four parameters: temperature (at least 3), pressure (5 and 20 bar), compositions of gases (pure $\mathrm{CH}_{4}, 80 \% \mathrm{H}_{2}-20 \% \mathrm{CH}_{4}$, pure $\mathrm{H}_{2}$ ) and polymer processing (pipe section and membrane). Most experiments have been carried out twice in order to evaluate the repeatability of the tests. For polymer membranes, the experimental device with two permeation cells is showed in Figure 1.

Considering the study of polymer pipe section, which is a geometry more representative of the application, two different permeation cells are available dependent on the geometry of the section pipe that is to say $(0.5 \mathrm{~m}$ length, $1 \mathrm{~mm}$ thickness) or (1 m length, $3 \mathrm{~mm}$ thickness) and are represented in Figure 2. These equipments have allowed us to compare data obtained on disc samples and pipes sections faced to various temperatures, pressures and different mixtures of natural gas and hydrogen in order to evaluate the processing influence on the barrier properties. The key point is that this experimental technique is very sensitive and allows the measurement of very small flows of diffusing molecules (up to $0.06 \mathrm{~mL} / \mathrm{h}$ ).

The permeation cell available at IMP (Fig. 3) consists in two compartments (upstream and downstream compartments) separated by the film to be studied. The cell is thermostated at a constant temperature chosen between 10 and $40^{\circ} \mathrm{C}$. A preliminary high vacuum desorption is performed to ensure that static vacuum pressure changes in the downstream compartment are smaller than the pressure changes due to the gas diffusion.

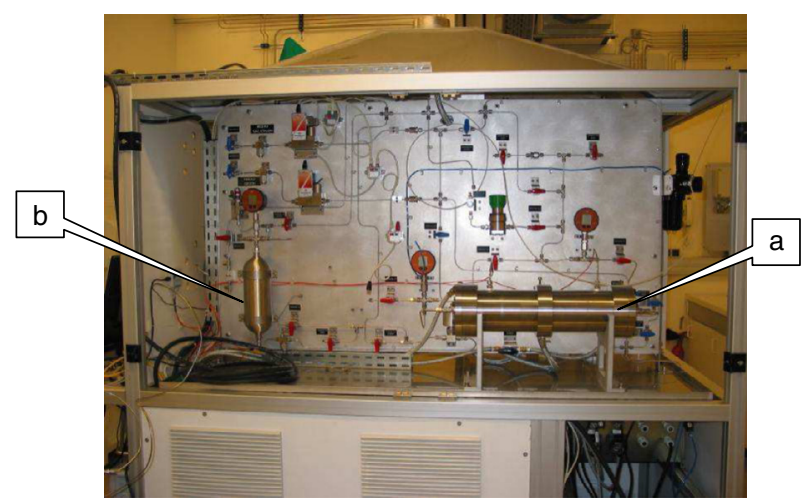

Figure 2

The two permeation cells dedicated to the study of polymer pipes sections of different lengths at IFPEN with a) one permeation cell and b) the gas tank. 

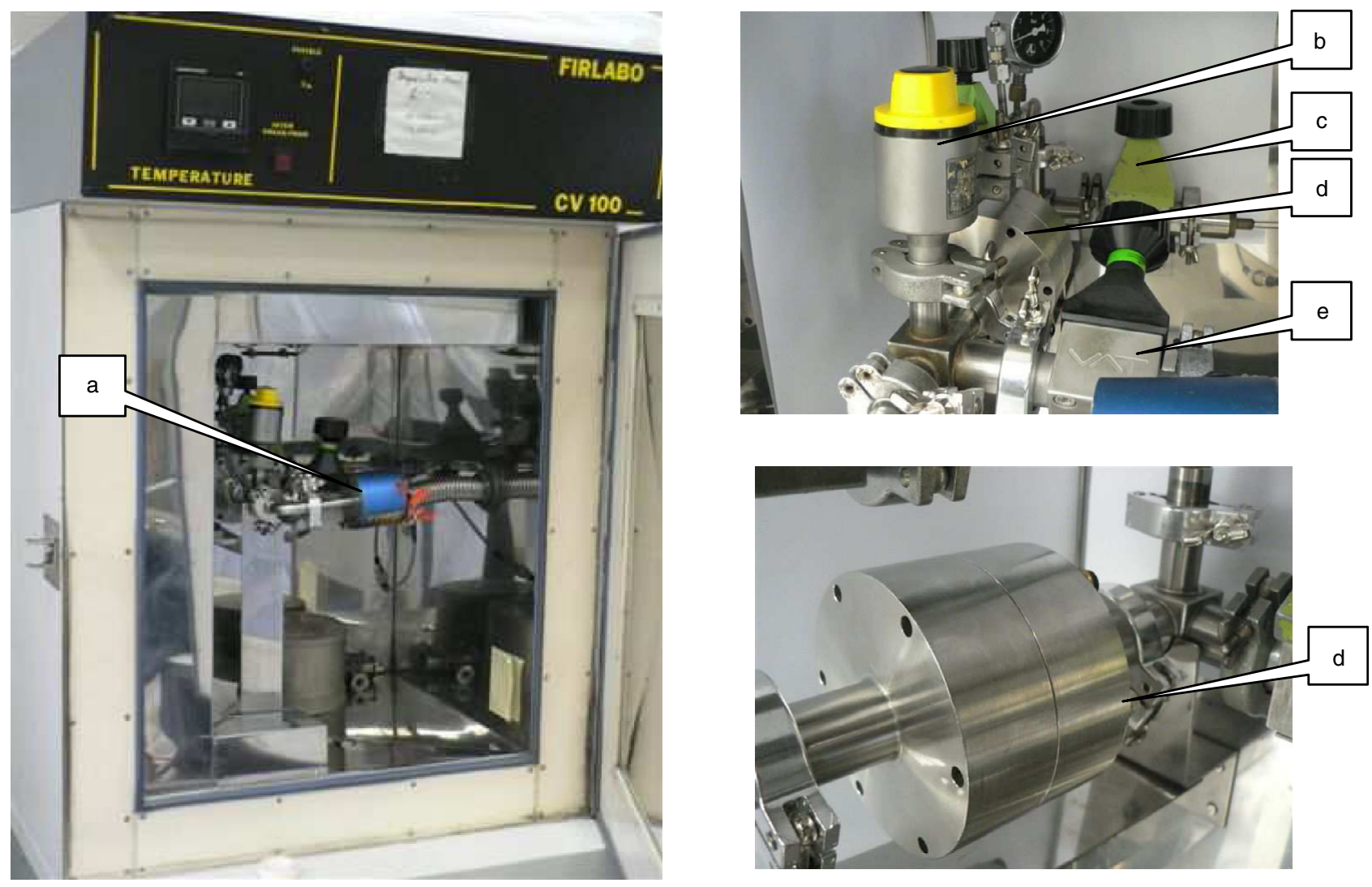

Figure 3

The permeation cell available at IMP with a) pressure sensor, b) by-pass, c) upstream pressure valve, d) permeation cell and e) downstream pressure valve.

For gas permeation experiments, a $5.0 \times 10^{5} \mathrm{~Pa}$ gas pressure of hydrogen or methane is introduced in the upstream compartment. The pressure variations in the downstream compartment are measured as a function of time with a 10 torr datametrics pressure sensor. The permeability coefficient $P e$ is calculated from the slope of the steady-state line.

\subsection{Long-Term Ageing Tests}

$C E A$ has participated in this project with the ageing of polymers under hydrogen and hydrogen/methane mixture, with the following tasks:

- ageing of polymer membranes and pipe sections by contact with hydrogen or hydrogen-methane $(80-20 \%)$ mixture under controlled pressure $(5,20$ bar $)$ and temperature $\left(20\right.$ to $\left.80^{\circ} \mathrm{C}\right)$ conditions;

- measurement and monitoring of the permeation coefficient during ageing of the samples;

- study of the variation of transport coefficients with time.
During ageing, the transfer of gas through the polymers is seen as a permeation mechanism governed by diffusion and classical laws can be applied.

The key point is that permeation measurements are made on a same polymer sample during its ageing without pressure relaxation thanks to the design of the ageing cells (Fig. 4). They comprise an upstream chamber that is continuously kept under the desired gas pressure thanks to a buffer reservoir, and a downstream chamber that is normally open to the atmosphere - the sample, membrane or tube, being sandwiched between the two chambers. Permeation measurements are made on an average every second month. Whenever they are required, the downstream chamber is flushed with a neutral gas (helium or nitrogen) that transports the permeated gases to a gas chromatograph allowing detection and quantification of the hydrogen or methane flux through the sample. This technique is basically the same as the one used for the permeation measurements (previous section). It allows in situ measurement of the permeation coefficients 


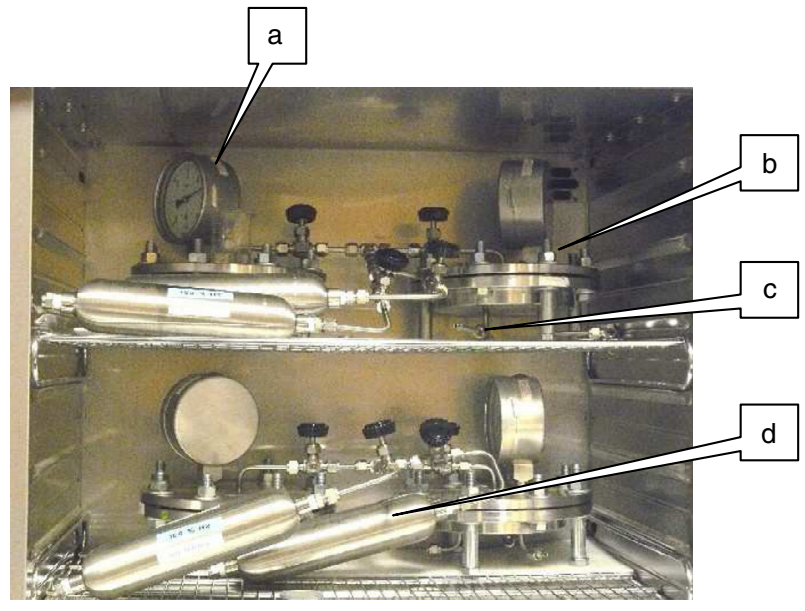

Figure 4

Ageing cells in an oven, connected to buffer $\mathrm{H}_{2}$ reservoirs with a) pressure indicator, $b$ ) test cell (membrane is between the 2 flanges), c) connections to measurement device (not connected on this picture) and d) buffer reservoirs.

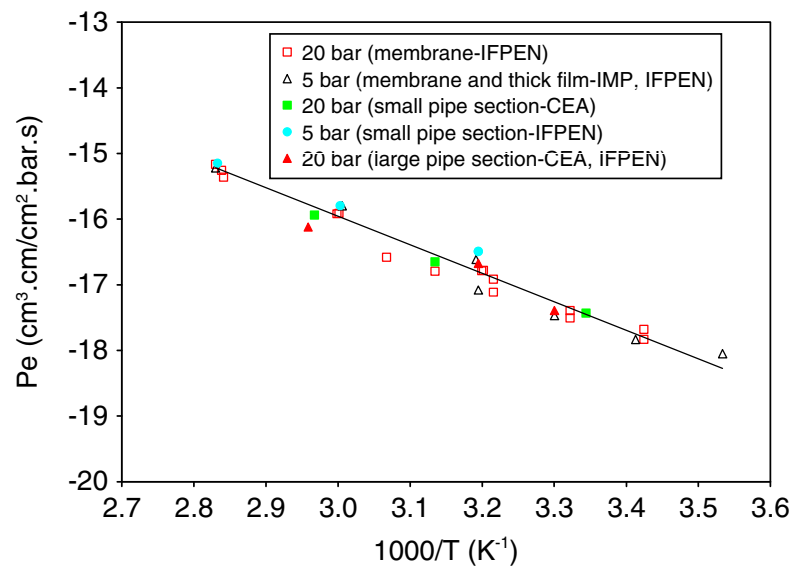

Figure 5

Evolution of the permeability coefficient with temperature in an Arrhenius representation for pure $\mathrm{H}_{2}$ through HDPE at two different pressures, for various geometries. The measurements have been performed on different devices. without having to remove the samples from the ageing cells and to disrupt the experimental conditions [20]. One drawback is that uncertainty is rather high $( \pm 20$ to $30 \%$ depending on operating conditions) because the equipment, especially the pressure indicators, have not been specifically selected for precise measurement of the permeation rate.

Temperature of the test cells is controlled by keeping them in an oven. The upstream chambers are filled with dry gas from a cylinder while the downstream chambers are open to the atmosphere and therefore exposed to ambient humidity.

A total of 17 membrane samples and 8 small-diameter $(8 \mathrm{~mm})$ and 8 large-diameter $(32 \mathrm{~mm})$ tubes have been submitted to ageing and periodic monitoring for 1 year.

\section{PERMEATION RESULTS}

Permeation properties of the three base materials were first measured and compared. An important point is that very few information concerning hydrogen permeation through these polymers and polymer assemblies can be found in the literature making this study particularly original.

\subsection{Characterization of the Monomaterial Systems}

\subsubsection{HDPE: Round Robin from $\mathrm{H}_{2}$ Permeation Experiments}

Permeation properties of a HDPE were studied and considered as reference properties, due to the use of this material in pipe manufacturing. All the measurements were performed either on HDPE membranes of around $1 \mathrm{~mm}$ thickness or on pipe sections of different radius at IFPEN and CEA. At IMP, the experimental device, initially developed for the study of thin films, was used for these thick samples. In all cases, tests were carried out twice in order to evaluate the repeatability of the tests. On the other hand, the influence of the parameters such as the temperature, the pressure and the geometry was studied.

All the different data obtained with pure hydrogen on HDPE membranes, pipes of various radius and in different conditions of temperature and two pressures have been reported in Figure 5. The evolution of the permeability coefficient was represented in a logarithmic scale as a function of the reciprocal of temperature. The first point is that, as expected, the permeability coefficient increases with temperature and is well represented by an Arrhenius law, that is to say that the plot of the logarithm of the permeability coefficient as a function of $1 / T$ defined a straight line. This is quite normal, because, in the temperature range studied, no transition temperature is associated either to the polymer or to the gases $[1,11,21]$. Moreover, from this curve and with the determination of the Arrhenius law relative to hydrogen (Tab. I), it is thus possible to calculate its permeability value at lower temperatures by extrapolation. It has to be noticed that, in the studied range of pressure, no influence of the pressure was found (from 5 to 20 bar).

The most important feature is that whatever the equipment used to determine permeation coefficients, 
TABLE 1

Activation energies and pre exponential terms for $\mathrm{H}_{2}$ and $\mathrm{CH}_{4}$ permeation through HDPE, PA11 and PAHM

\begin{tabular}{l|c|c|c|c|c|c}
\hline Polymer-gas system & HDPE- $H_{2}$ & $\mathrm{HDPE}_{-} \mathrm{CH}_{4}$ & $\mathrm{PA}_{11-\mathrm{H}_{2}}$ & $\mathrm{PA}_{11-\mathrm{CH}_{4}}$ & $\mathrm{PAHM}_{2}$ & $\mathrm{PAHM}_{2} \mathrm{CH}_{4}$ \\
\hline $\mathrm{E}_{\mathrm{P}}(\mathrm{kJ} / \mathrm{mol})$ & 36 & 38 & 38 & 46 & 25 & 55 \\
\hline $\mathrm{Pe}_{0}\left(\mathrm{~cm}^{3} \cdot \mathrm{cm}^{-1} \cdot \mathrm{s}^{-1} \cdot \mathrm{bar}^{-1}\right)$ & $5.4 \times 10^{-2}$ & $4.2 \times 10^{-2}$ & $6.3 \times 10^{-2}$ & $9.4 \times 10^{-2}$ & $4.8 \times 10^{-4}$ & $8.6 \times 10^{-1}$ \\
\hline
\end{tabular}

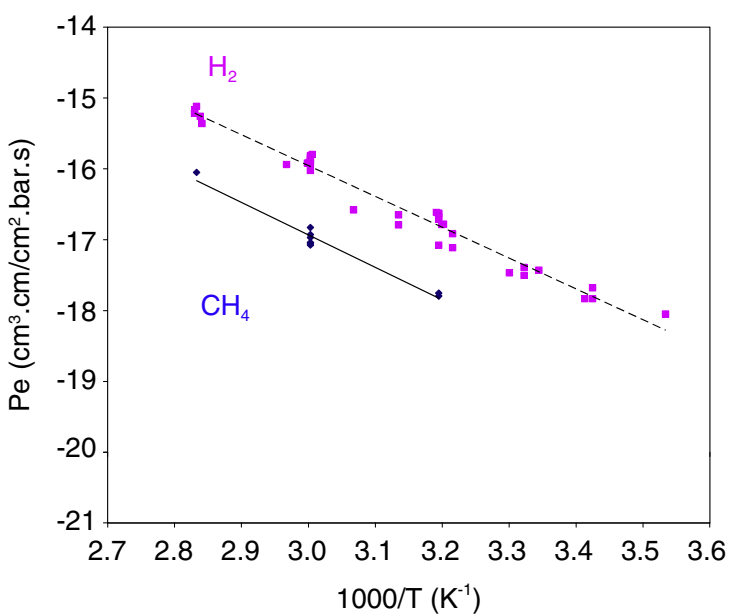

Figure 6

Evolution of the permeability coefficients of $\mathrm{H}_{2}$ and $\mathrm{CH}_{4}$ through HDPE for pure and mixtures of gases, various geometries (membranes and pipes of various sections).

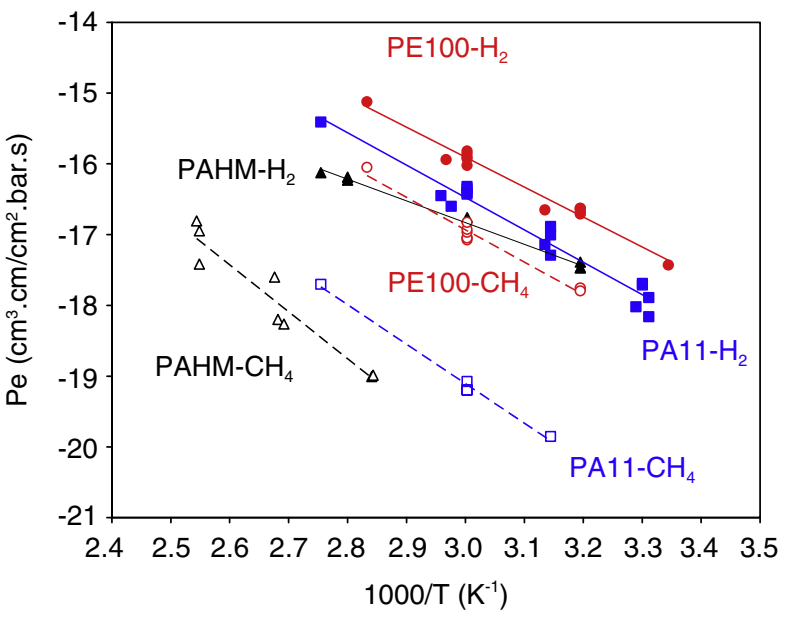

Figure 7

Comparison of the permeability coefficients of $\mathrm{H}_{2}$ and $\mathrm{CH}_{4}$ through HDPE, PA11 and PAHM (for different pipe sections, pure gas and mixtures at two pressures). The closed symbols are relative to $\mathrm{H}_{2}$ and the open symbols to $\mathrm{CH}_{4}$. all the experimental data were found to be in good agreement and did not present a significant discrepancy (maximal value of $20 \%$ ). These round-robin tests have validated that the various methods used by the project's partners, to detect and quantify the diffusing molecules through the polymer are reproducible. Furthermore, it has shown that for HDPE, there is no influence of the processing conditions on its barrier properties.

\subsubsection{HDPE: Comparison for $\mathrm{H}_{2}, \mathrm{CH}_{4}$ and their Gas Mixtures}

Figure 6 shows the evolution of the permeability coefficients obtained for $\mathrm{H}_{2}$ and $\mathrm{CH}_{4}$ through HDPE in a representation of Arrhenius' plot. It has to be noticed that some data have been obtained with pure gases and some other with mixtures $\left(80 \% \mathrm{H}_{2}-20 \% \mathrm{CH}_{4}\right)$. Results showed that the permeability of hydrogen is higher than that of methane. The activation energy values obtained for $\mathrm{H}_{2}$ and $\mathrm{CH}_{4}$ are roughly the same
(36 and $38 \mathrm{~kJ} / \mathrm{mol}$, (Tab. 1), the uncertainty on these calculated data can be estimated at least $10 \%$ ). On that plot, data relative to pure $\mathrm{H}_{2}$ or $\mathrm{H}_{2}$ in a mixture are represented with the same symbols as they were really close considering the natural scattering. The same remark applies to methane independently of the sample geometry. This implies that in the case of mixtures of hydrogen and natural gas, no particular interaction could be noticed so no mixture effect. Consequently, for a given temperature, each gas (either $\mathrm{H}_{2}$ or $\mathrm{CH}_{4}$ ) keeps its intrinsic permeability coefficient independently of the other gas.

\subsubsection{Comparison of Polyamide Systems with HDPE}

The next step has consisted in determining the transport properties of $\mathrm{CH}_{4}$ and $\mathrm{H}_{2}$ through PA11 and comparing them with those obtained on PE as illustrated by Figure 7 . The experimental values obtained 
for the two polyamides as for PE in the different laboratories were found to be in good agreement and for each polymer, the permeability coefficient follows an Arrhenius law.

In the case of hydrogen, the permeation values have been determined at temperatures below and above the glass transition temperature in the polyamides. As its size is really small, the hydrogen molecule is not sensitive to differences in polymer chain mobility associated with the transition between glassy and rubbery state [22]. For methane, all the tests have been performed at temperatures above $T g$.

Moreover, by comparing the behaviour of the two gases, one can see that the permeability of $\mathrm{H}_{2}$ is larger than that of $\mathrm{CH}_{4}$ whatever the considered temperature is and whatever the polymer is. On the other hand, no influence of the applied pressure could be detected in the studied range (5 to 20 bar) and no mixture effect.

The permeability coefficients decreased going from HDPE to polyamide 11 . Although the crystallinity was higher for PE than for PA11, the barrier properties were higher for PA11 than for PE. The gas barrier properties were then closely related to the cohesive energy density of the amorphous phase in each polymer. Indeed, the polar structure of polyamide type polymer allows the formation of intra and intermolecular hydrogen bonds leading to a higher cohesion in the amorphous phase and as a consequence to lower gas permeability [1]. The permeability decrease observed between PE and PA11 is higher for methane than for hydrogen which is in accordance with the size difference of the two molecules.

The $\mathrm{H}_{2}$ permeability coefficients of PA11 and of the new high performance polyamide were in the same range showing the interest of this last material for target pipeline for which combined high mechanical and barrier performances are required. The activation energy corresponding to the permeation of $\mathrm{H}_{2}$ through PAHM is slightly lower than in PA11. This surprising result can probably be related to a higher cohesive energy density of the polymer amorphous phase associated to a significant rigidity of the polymer chains. Indeed, as aforementioned, PAHM has the lowest crystallinity degree and the highest glass transition temperature. Comparing the permeation level of both polyamides with the two gases, it appears that the new grade PAHM seems to present better barrier properties. It can lastly be noticed that the hydrogen permeability coefficient of PA11 and PAHM is in the same range as the one of methane for PE showing the interest of these two materials for new pipes development. Polyamide 11 pipes are already commercially available which makes them an interesting solution for hydrogen distribution.

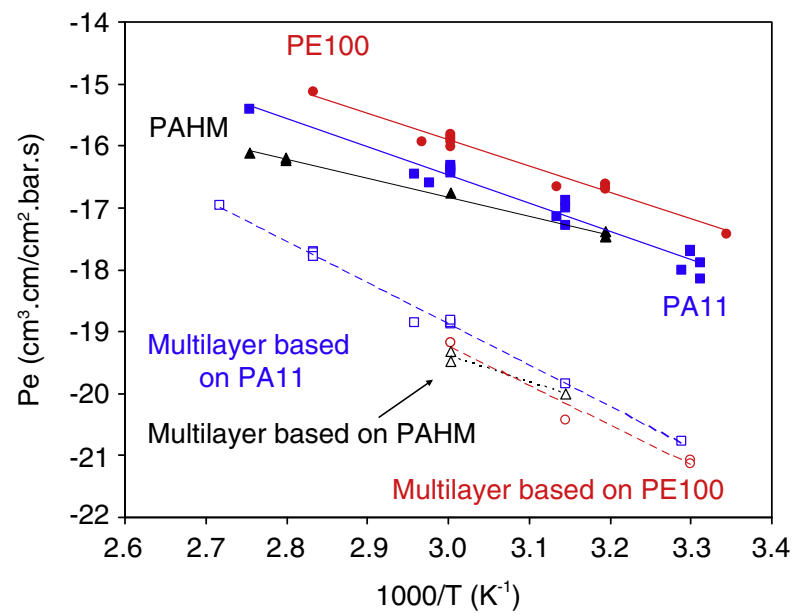

Figure 8

Permeability coefficients of all the tested systems to hydrogen as a function of temperature in an Arrhenius representation.

\subsection{Study of Multilayers Systems}

The effect of the addition of a gas barrier layer of EVOH to the different polymers was investigated with respect to hydrogen permeation.

Multilayers pipes based on PE, PA11 and PAHM respectively, including a thin gas barrier layer composed of EVOH (thickness between 50 and $160 \mu \mathrm{m}$ ), have been provided with the same geometrical characteristic as for the monolayer pipes. The permeation data relative to hydrogen and the different systems i.e. monolayers (PE, PA11, PAHM) or multilayers configurations (based on the homopolymer but comprising an EVOH layer) are illustrated in Figure 8.

The hydrogen permeability coefficient in presence of EVOH is strongly decreased compared to a pipe made of pure PE or PA (PA11 or PAHM). This demonstrates that the layer of EVOH drives the gas barrier properties of these multilayer systems as there is no significant difference between them. By the way, the activation energies in the multilayer systems are higher than in the monolayer references (around $54 \mathrm{~kJ} / \mathrm{mol}$ compared to 37). It has to be noticed that this energy is lower in the case of the multilayer based on PAHM which agrees with the results obtained on monolayer systems.

Lastly, compared to the permeability coefficient of methane through PE, the $\mathrm{H}_{2}$ permeability coefficient through multilayer systems is 15 to 30 times smaller. It can be concluded that EVOH is effective as a gas barrier layer but to conclude on the feasibility of this solution, the behaviour in fatigue has to be assessed. 


\subsection{Ageing Effect on HDPE and PA1 1}

The ageing of materials under hydrogen environment is a crucial point. Indeed, hydrogen embrittlement of steels is considered as a potential risk for transmission and for distribution pipeline explaining why polymers are preferred. Different ageing parameters such as the pressure, the temperature, hydrogen effect have been studied here on the durability of HDPE and PA11.

For PE and PA11, a great number of membranes and small or large diameter pipes have been submitted to ageing and periodic monitoring for 1 year. Exploitation of the measurements on membranes has been made according to the methodology exposed in the experimental part. Since the permeation coefficient has been shown to follow Arrhenius' law, the measurements are all converted to an equivalent at $20^{\circ} \mathrm{C}$ by using Equation (5) with the value for $E_{p}$ in Table 1 . Besides, the permeation coefficient has been found independent of pressure and gas composition, which makes direct comparison possible in spite of the various experimental conditions (Fig. 9, 10, for HDPE and PA11 respectively).

The most important result is that under our conditions of ageing, the permeation coefficient is constant, equal to $2 \times 10^{-8} \mathrm{~cm}^{3} \cdot \mathrm{cm}^{-1} \cdot \mathrm{s}^{-1} \cdot \mathrm{bar}^{-1}$ for PE sample and $8 \times 10^{-9} \mathrm{~cm}^{3} \cdot \mathrm{cm}^{-1} \cdot \mathrm{s}^{-1} \cdot \mathrm{bar}^{-1}$ for PA11 sample at $20^{\circ} \mathrm{C}$ under $\mathrm{H}_{2}$, within measurement uncertainty. It is unaffected by one year of ageing, whatever the experimental conditions. Analysis of the available results for tube samples suggests that the same ratio exists between the permeation coefficients of PE and PA11 tubes and that they are also essentially unaltered by ageing.

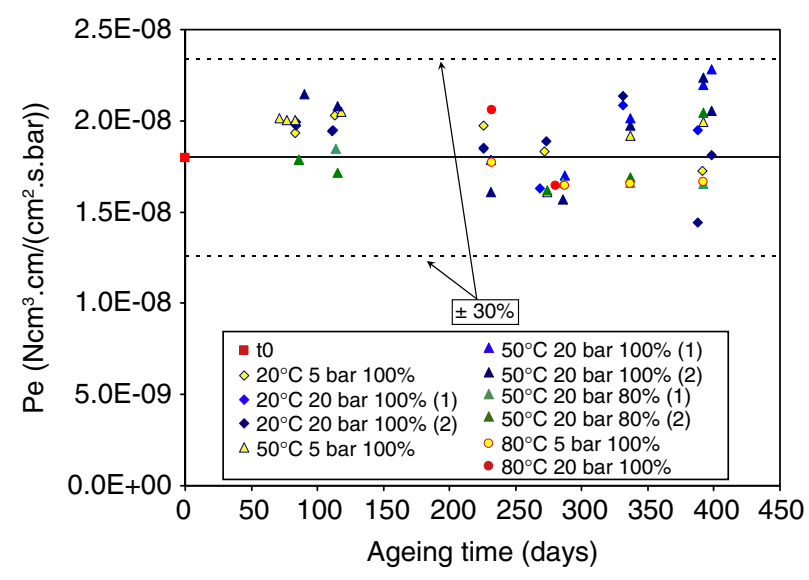

Figure 9

Evolution of the $\mathrm{H}_{2}$ permeability coefficient in HDPE at $20^{\circ} \mathrm{C}$ as a function of ageing time (various conditions of $T, P$, gas composition).

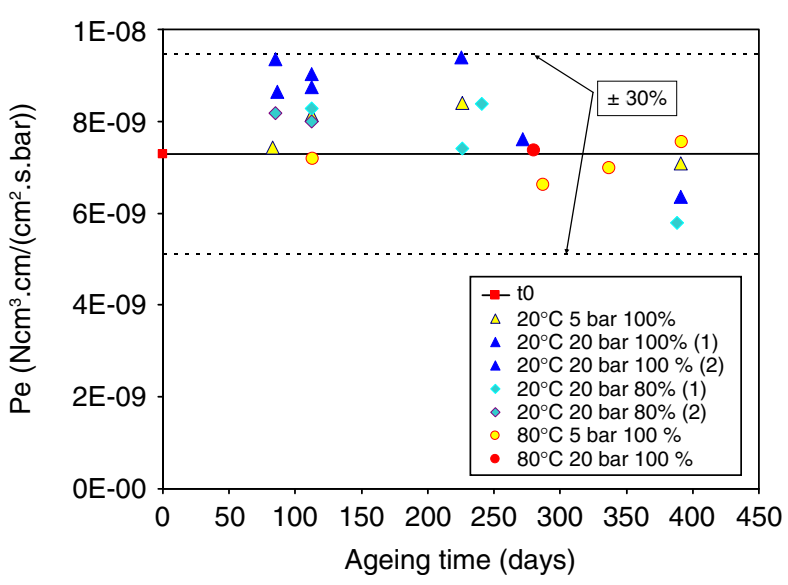

Figure 10

Evolution of the $\mathrm{H}_{2}$ permeability coefficient in PA11 at $20^{\circ} \mathrm{C}$ as a function of ageing time (various conditions of $T, P$, gas composition).

\section{CONCLUSION}

Permeation measurements were performed on unaged PE100 material samples in various conditions of pressure, hydrogen content and temperature and moreover in different laboratories. First of all, there is no significant discrepancy between the results obtained on various equipments, the reproducibility of data is very good.

Our second objective was to study the possible mixing effects of gases on the transport properties of a polymer membrane. These effects are observed by comparing the membrane performance with respect to the mixed feed gas composition $\left(80 \% \mathrm{H}_{2}-20 \% \mathrm{CH}_{4}\right)$.

Some results obtained by using specific permeability equipments dedicated to gas mixtures have been presented. The key point is that, in the case of mixture of methane and hydrogen through PE100, no particular gas-gas or gas-polymer interaction has been revealed whatever the composition as well as no pressure effect.

Concerning the evolution of permeability with temperature, it is well represented by an Arrhenius law in the range $\left(10-85^{\circ} \mathrm{C}\right)$. It is thus allowed to extrapolate permeability coefficients at lower temperatures if no characteristic transition relative to the polymer occurs.

Two types of polyamide materials were compared to a high density polyethylene. The hydrogen permeation of these two polyamides has been shown to be equivalent to that of methane through PE, which makes them interesting for hydrogen distribution. The effect of the addition of a gas barrier such as EVOH to PE and PA11 was also investigated with respect to hydrogen permeation (before and after an exposure to hydrogen) and found to be beneficial.

Furthermore, new specific devices for the evaluation of gas permeability through pipes have been developed to test 
pipes sections under hydrogen in service conditions (pressure, temperature, composition of the mixture of natural gas and hydrogen). In the case of PE100 and PA11, a good correlation of the measurements between pipe sections and discs samples was obtained which means that no influence of the polymer processing could be noticed.

But the most important point is that the effect of ageing under an hydrogen environment has also been studied. No evolution of the barrier properties of the PE100 or the PA11 system has been observed after more than one year of ageing in the presence of hydrogen whatever the conditions (in terms of pressure, temperature, gas composition).

Polymer materials tested in PolHYtube project such as multilayers systems based on a EVOH layer seem very promising and interesting solutions for the different identified targets in hydrogen distribution.

\section{ACKNOWLEDGMENTS}

Authors would like to gratefully acknowledge funding from the French National Agency of Research (ANR) (PolHYTube project; PAN-H program) and partnerships of the project: Arkema and G. Hoschstetter for providing the materials, Air Liquide, Institut P'.

\section{REFERENCES}

1 Crank J., Park G.S. (1968) Diffusion in polymers, Academic Press, London and New-York, pp. 1-414.

2 Klopffer M.H., Berne P., Castagnet S., Weber M., Hochstetter G., Espuche E. (2010) Polymer pipes for distributing mixtures of hydrogen and natural gas: evolution of their transport and mechanical properties after an ageing under an hydrogen environment, 18th World Hydrogen Energy Conference 2010, WHEC 2010, Essen, Germany.

3 Lafitte G., Espuche E., Gerard J.F. (2011) Polyamide 11/ poly(hydroxy amino ether) blends: Influence of the blend composition and morphology on the barrier and mechanical properties, European Polymer Journal 47, 10, 1994-2002.

4 Klopffer M.H., Berne P., Weber M., Castagnet S., Hochstetter G., Espuche E. (2012) New materials for hydrogen distribution networks: materials development \& technico-economic benchmark, Diffusion in materials DIMAT 2011, Defect and Diffusion Forum, 407-412.

5 Stannett V. (1978) The transport of gases in synthetic polymer membranes - an historic perspective, Journal of Membrane Science 3, 97-115.
6 Naylor T.V. (1989) Permeation properties, in Comprehensive Polymer Science, Pergamon Press.

7 Crank J. (1975) The Mathematics of Diffusion, Oxford University Press, Oxford.

8 Koros W.J., Hellums M.W. (1985) Transport properties, Encyclopedia of Polymer Science and Technology, John Wiley \& Son's.

9 Neogi P. (1996) Transport Phenomena in Polymer Membranes, Diffusion in Polymers, Marcel Dekker Inc, New-York.

10 Rogers C.E. (1964) Permeability and Chemical Resistance, in Engineering Design for Plastics, Baer E. (ed.), Reinhold, New-York.

11 Rogers C.E. (1985) Permeation of gases and vapours in polymers, in Polymer Permeability, Comyn J. (ed.), Elsevier Applied Science.

12 Stern S.A. (1994) Polymers for gas separation, Journal of Membrane Science 94, 1-65.

13 Barrer R.M. (1937) Nature of the diffusion process in rubber, Nature 140, 106-107.

14 Michaels A.S., Parker R.B. (1959) Sorption and flow of gases in polyethylene, Journal of Polymer Science 41, 53-71.

15 Michaels A.S., Bixler H.J. (1961) Solubility of gases through polyethylene, Journal of Polymer Science 50, 393-412.

16 Michaels A.S., Bixler H.J. (1961) Flow of gases through polyethylene, Journal of Polymer Science 50, 413-439.

17 Cai Y., Wang Z., Yi C.H., Bai Y.H., Wang J.X., Wang S.C. (2008) Gas transport property of polyallylamine-poly(vinyl alcohol)/polysulfone composite membranes, Journal of Membrane Science 310, 1-2, 184-196.

18 Klopffer M.H., Flaconnèche B., Esterlé K., Lafontaine M. (2005) Experimental method of permeability measurements of $\mathrm{H}_{2}$ and $\mathrm{H}_{2}-\mathrm{CH}_{4}$ mixtures through Polyethylene, 2nd European Hydrogen Energy Conference, EHEC 2005, Zaragoza, Spain.

19 Klopffer M.H., Flaconnèche B., Odru P. (2007) Transport properties of gas mixtures through polyethylene, Plastics, Rubber and Composites 36, 5, 184-189.

20 Foulc M.P., Nony F., Mazabraud P., Berne P., Klopffer M.H., Flaconnèche B., Ferreira Pimenta G., Müller Syring G., Alliat I. (2006) Durability and transport properties of polyethylene pipes for distributing mixtures of hydrogen and natural gas, 16th World Hydrogen Energy Conference 2006, WHEC 2006, Lyon.

21 Klopffer M.H., Flaconnèche B. (2001) Transport properties of gases in polymers: Bibliographic review, Oil \& Gas Science and Technology 56, 3, 223-244.

22 Costello L.M., Koros W.J. (1994) Effect of Structure on the Temperature-Dependence of Gas-Transport and Sorption in A Series of Polycarbonates, Journal of Polymer Science Part B-Polymer Physics 32, 4, 701-713.

Manuscript accepted in January 2014 Published online in July 2014

Cite this article as: M-H. Klopffer, P. Berne and É. Espuche (2015). Development of Innovating Materials for Distributing Mixtures of Hydrogen and Natural Gas. Study of the Barrier Properties and Durability of Polymer Pipes, Oil Gas Sci. Technol 70, 2, 305-315. 